\title{
Brief
}

\section{Extramedullary plasmacytoma immunoglobulin $D(\lambda)$ in the chest wall and the subglottic region}

\author{
Shoji Sakiyama, MD, PhD, ${ }^{a}$ Kazuya Kondo, MD, PhD, ${ }^{\text {a }}$ Yoshida Mitsuteru, MD, ${ }^{a}$ Hiromitsu Takizawa, MD, \\ Koichiro Kenzaki, MD, ${ }^{\text {a }}$ Takanori Miyoshi, MD, PhD, ${ }^{a}$ Masahiro Abe, MD, PhD, ${ }^{\text {b }}$ Shingo Wakatsuki, MD, $\mathrm{PhD},{ }^{\mathrm{c}}$ and \\ Yasumasa Monden, MD, PhD, ${ }^{\text {a }}$ Tokushima, Japan
}

\footnotetext{
From the Departments of Oncological and Regenerative Surgery, ${ }^{a}$ Medicine and Bioregulatory Sciences, ${ }^{b}$ and Pathology, ${ }^{c}$ Graduate School of Medicine, The University of Tokushima, Tokushima, Japan.

Received for publication Aug 8, 2004; accepted for publication Aug 23, 2004.

Address for reprints: Shoji Sakiyama, MD, PhD, Department of Oncological and Regenerative Surgery, Graduate School of Medicine, The University of Tokushima, Kuramoto-cho 3, Tokushima 770-8503, Japan (E-mail: sakiyama@clin. med.tokushima-u.ac.jp).

J Thorac Cardiovasc Surg 2005;129:1168-9

$0022-5223 / \$ 30.00$

Copyright (C) 2005 by The American Association for Thoracic Surgery

doi:10.1016/j.jtcvs.2004.08.037
}

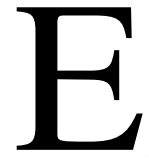

xtramedullary plasmacytoma is a rare plasma cell neoplasm that occurs in the absence of systemic signs of multiple myeloma, and most often occurs in the upper aerodigestive tract of the head and neck. ${ }^{1}$ We report a case of extramedullary plasmacytoma with immunoglobulin $(\operatorname{Ig}) \mathrm{D}(\lambda)$ in the chest wall and the subglottic region that showed an interesting clinical course.

\section{Clinical Summary}

A 47-year-old woman visited our hospital with chief symptoms of a fist-sized tumor and invariable pain in the left lateral pectoral region. The tumor was elastic and hard, with radiating pressure pain. The chest radiograph showed an ill-defined $7.0 \times 5.0$-cm mass shadow in the left lower lung field (Figure 1, A). The chest radiograph obtained during a mass chest radiograph survey about 10 months before the visit appeared normal. Chest computed tomography demonstrated a heterogeneously enhanced mass without destruction of the ribs in the left chest wall (Figure 1, B). Magnetic resonance imaging showed no osteolytic lesion in the ribs. Preoperative histopathologic diagnosis of the incisional biopsy sample was high-grade sarcoma.

The patient was scheduled for a chest wall resection and reconstructive surgery. On the day of the operation, the anesthetist discovered a subglottic tumor while intubating the patient (Figure 2, A). There had been no symptoms of dyspnea or change of voice before the operation. After a tracheotomy, a chest wall dissection was performed, encompassing an area of $15.0 \times 12.5 \mathrm{~cm}$ starting from the lower edge of the seventh rib to the upper edge of the 11th rib. The defect of the chest wall was reconstructed with polytetrafluoroethylene mesh and a skin flap.

The excised chest wall tumor, measuring $9.0 \times 7.3 \times 5.0 \mathrm{~cm}$, surrounded ribs. Examination of a permanent section revealed that the chest wall tumor was $\operatorname{IgD}(\lambda)$ type plasmacytoma. Ki-67 proliferation index (the proportion of proliferating cells in the tumor) of the tumor showed a value of $40 \%$. After the operation, M-protein was not detected in the blood or urine. Bone marrow examination showed normal findings. The results of a radiographic survey did not show any lesion.

Although biopsy had been performed several times on the subglottic tumor, we had not been able to achieve a definite diagnosis. The subglottic tumor had regressed spontaneously by about 10 weeks after the chest wall operation (Figure 2, B). Two months later, the patient was urgently readmitted to our hospital with the symptom of airway stenosis caused by rapid regrowth of the subglottic tumor that reached the vocal cord (Figure 2, C). The subglottic tumor was identified as $\operatorname{IgD}(\lambda)$ type plasmacytoma. Systemic resurvey did not show any other lesions. The subglottic tumor was treated with radiotherapy in doses of $50 \mathrm{~Gy}$ and one cycle of chemotherapy with vincristine, doxorubicin, and dexamethasone. The subglottic tumor has been well controlled (Figure 2,D).

The patient was successfully treated and shows no signs of recurrence or development of multiple myeloma 7 years after this treatment.

\section{Discussion}

Extramedullary plasmacytomas in the chest wall are extremely uncommon. Most plasmacytomas in the chest wall arise in bone. ${ }^{2}$ 

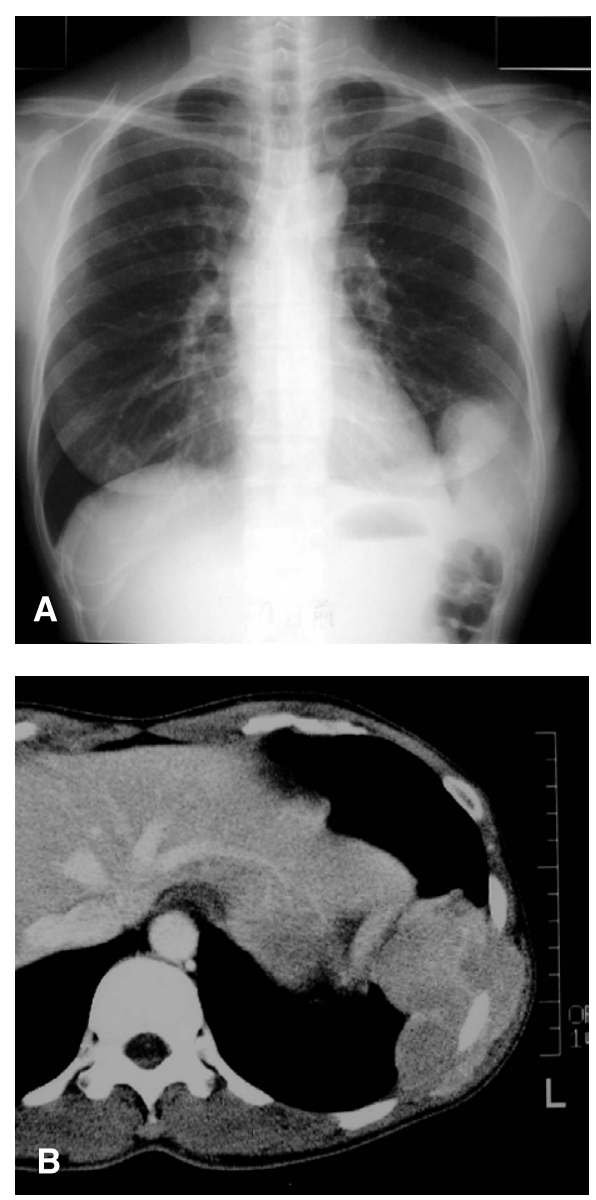

Figure 1. A, Chest radiograph showing ill-defined mass shadow. B, Chest computed tomographic scan showing soft-tissue density mass without destruction of the ribs.

In our case, the tumor in the chest showed a rapid growth within about 10 months, and the regrowth tumor of the subglottic region also showed a rapid growth within about 2 months. This chest wall tumor showed a high proliferative index detected by $\mathrm{Ki}-67$. Although an elevated value of $\mathrm{Ki}-67$ is considered to be a poor prognostic factor in multiple myeloma, Galieni and colleagues ${ }^{3}$ postulated that extramedullary plasmacytoma has a different origin, and consequently different biologic behavior, than multiple myeloma or plasmacytoma of the bone, with a more favorable prognosis for extramedullary plasmacytoma.

Although the reason that the subglottic extramedullary plasmacytoma showed temporary but dramatic regression after the operation on the chest wall extramedullary plasmacytoma remains unknown, we speculate that the regression may have interleukin (IL) 6 implications. IL-6 is a potent myeloma cell growth factor involved not only in vitro but also in vivo, and there is clear evidence to support both autocrine and paracrine mechanisms of IL-6 in myeloma. ${ }^{4}$ The subglottic tumor may have regressed after the resection of the chest wall tumor because of the reduction of

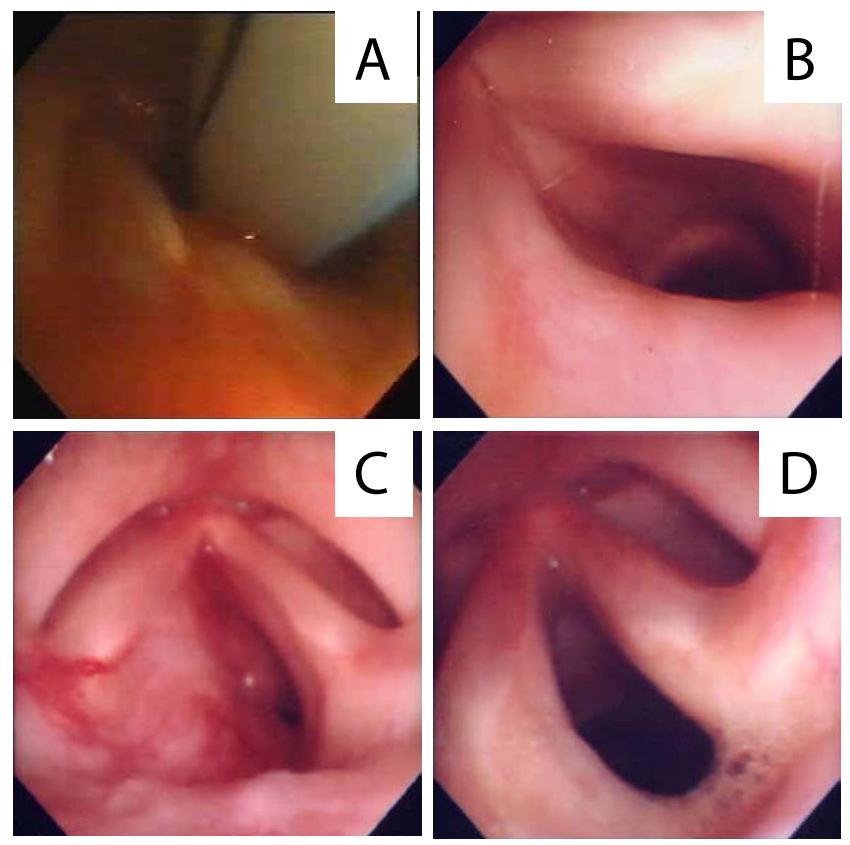

Figure 2. A, Bronchoscopy showing subglottic tumor during chest wall resection surgery. A tube of $6 \mathrm{~mm}$ internal diameter was used for intubation. B, Subglottic tumor reducing after operation for chest wall tumor. C, Subglottic tumor shown to have regrown rapidly within 2 months after chest resection procedure. Subglottic tumor involving left-sided vocal cord almost obstructs airway. D, Subglottic tumor has been controlled after chemoradiation therapy.

the IL-6 signal. Another possible explanation for the regression may have been nonsteroidal anti-inflammatory agent. Nonsteroidal anti-inflammatory agents have been shown to inhibit the development of plasmacytoma in a murine model. ${ }^{5}$ A nonsteroidal antiinflammatory agent used as an analgesic after operation may have effected a temporary regression of the tumor.

We report a case of extramedullary plasmacytoma involving the chest wall and the subglottic region characterized by $\operatorname{IgD}(\lambda)$, rapid growth, and temporal spontaneous regression.

\section{References}

1. Alexiou C, Kau RJ, Dietzfelbinger H, Kremer M, Spiess JC, Schratzenstaller B, et al. Extramedullary plasmacytoma: tumor occurrence and therapeutic concepts. Cancer. 1999;85:2305-14.

2. Burt M, Karpeh M, Ukoha O, Bains MS, Martini N, McCormack PM, et al. Medical tumors of the chest wall. Solitary plasmacytoma and Ewing's sarcoma. J Thorac Cardiovasc Surg. 1993;105:89-96.

3. Galieni P, Cavo M, Pulsoni A, Avvisati G, Bigazzi C, Neri S, et al. Clinical outcome of extramedullary plasmacytoma. Haematologica. 2000;85:47-51.

4. Lauta VM. A review of the cytokine network in multiple myeloma: diagnostic, prognostic, and therapeutic implications. Cancer. 2003;97: 2440-52.

5. Potter M, Wax J, Jones GM. Indomethacin is a potent inhibitor of pristane and plastic disc induced plasmacytomagenesis in a hypersusceptible BALB/c congenic strain. Blood. 1997;90:260-9. 